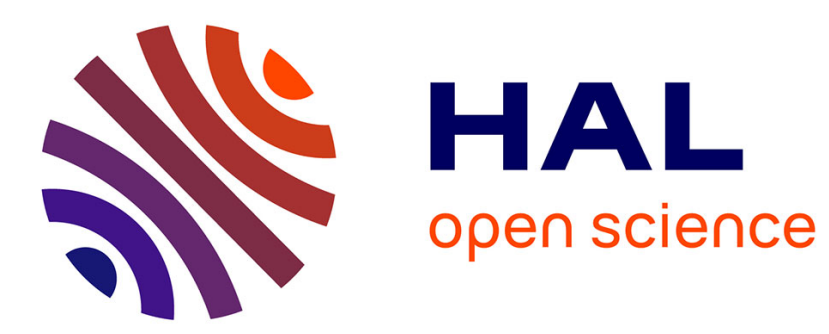

\title{
Evaluation of quality of life therapy for parents of children with obsessive-compulsive disorders in Iran
}

\author{
Mohammad Reza Abedi, Panos Vostanis
}

\section{To cite this version:}

Mohammad Reza Abedi, Panos Vostanis. Evaluation of quality of life therapy for parents of children with obsessive-compulsive disorders in Iran. European Child and Adolescent Psychiatry, 2010, 19 (7), pp.605-613. 10.1007/s00787-010-0098-4 . hal-00566319

\section{HAL Id: hal-00566319 https://hal.science/hal-00566319}

Submitted on 16 Feb 2011

HAL is a multi-disciplinary open access archive for the deposit and dissemination of scientific research documents, whether they are published or not. The documents may come from teaching and research institutions in France or abroad, or from public or private research centers.
L'archive ouverte pluridisciplinaire HAL, est destinée au dépôt et à la diffusion de documents scientifiques de niveau recherche, publiés ou non, émanant des établissements d'enseignement et de recherche français ou étrangers, des laboratoires publics ou privés. 


\title{
Evaluation of quality of life therapy for parents of children with obsessive-compulsive disorders in Iran
}

\author{
Mohammad Reza Abedi · Panos Vostanis
}

Received: 3 February 2009/Accepted: 29 January 2010/Published online: 16 February 2010

(C) Springer-Verlag 2010

\begin{abstract}
Previous research has provided evidence on the effectiveness of CBT in the symptomatic improvement of children with obsessive-compulsive disorders. There is also increasing recognition of the importance of involving parents and families in treatment. The aim of this study was to evaluate the short-term effectiveness of such an intervention that promoted family strengths [(quality of life therapy (QoLT)] for mothers of children with obsessivecompulsive disorders (OCD). The sample consisted of 40 children with OCD and their mothers, who had been referred to clinics in Esfahan city in Iran. Mothers were randomly allocated to an experimental (QoLT) and waiting list control group. Mothers participated in eight QoLT group sessions over 4 weeks. QoLT incorporated CBT techniques in managing OCD symptoms. Measures were completed pre- and post-intervention by both groups. Children completed the Yale-Brown obsession compulsion scale for Children, the Revised children's manifest anxiety scale, and the brief multidimensional student's life satisfaction scale; mothers completed the quality of life inventory (QoLI). QoLT was associated with decrease in OCD and anxiety symptoms and increase in children's satisfaction in the global, family and environment domains, as well as with increased QoLI scores in their mothers.
\end{abstract}

\footnotetext{
M. R. Abedi

Faculty of Education and Psychology,

University of Esfahan, Hezarjerib Street,

Esfahän, Iran

e-mail: dr.mr.abedi@gmail.com

P. Vostanis $(\square)$

Greenwood Institute of Child Health,

University of Leicester, Westcotes House,

Westcotes Drive, Leicester LE3 0QU, UK

e-mail: pv11@le.ac.uk
}

Parenting interventions like QoLT can complement individual modalities such as CBT in the presence of familyrelated difficulties. This can be particularly applicable in countries and settings with limited resources and high stigma of child mental health problems.

Keywords Obsessive-compulsive disorder (OCD) . Quality of life therapy (QoLT) · Intervention · Children · Parents

\section{Introduction}

Recent years have seen an increase in evidence on the indications and effectiveness of different treatment modalities for OCD. A substantial number of studies have evaluated the use of cognitive-behavioural therapy (CBT) involving exposure and response prevention [6, 31, 32]. Interventions for OCD, as indeed as for other child psychiatric disorders, have also taken into increasing consideration the involvement of parents and families [28]. For example, CBT packages for childhood OCD often recommend a therapeutic emphasis on psycho education and family involvement [20]. Families of children with OCD have been shown to have some characteristics that are different from those of most other disorders which could therefore be important in setting up family interventions. Previous studies have shown that parents may have fewer coping strategies [3], be rigid and over involved [17], or have high expectations of their children [4].

Different parenting and family interventions have thus been developed to particularly address some of these characteristics, in addition to alleviating children's psychopathology. Steketee and Van Nappen [28] reviewed family approaches to treatment for OCD, and concluded 
that the use of relatives in treatment had benefits for children, especially multiple-family groups that focus on exposure and prevention of rituals. Families could be involved in interventions through a combination of family and individual CBT; use of cognitive-behavioural techniques in family therapy (when symptoms affect the rest of the family), with the parents participating in all joint treatment sessions and using similar techniques to individual CBT; and behavioural family therapy (when the family shows significant dysfunction), with the parents participating in formal parent training and the child participating in individual CBT [6].

Knox et al. [14] described a training programme for parents in differential reinforcement, enhancement of adaptive coping behaviours, psycho education, home-based exposure and response prevention, and this was associated with significant improvement. Waters et al. [31] found that cognitive-behavioural family treatment led to considerable benefits for children's OCD symptoms. Treatment included supporting the family through exposure and response prevention, parental anxiety management, psycho education about OCD, and problem-solving training.

Previously described interventions predominantly aimed at improving children's symptoms. In recent years, positive psychology researchers have also focused on developing strengths, facilitating positive responses to adversity, strengthening family relationships [25], especially increasing life satisfaction and quality of life [10]. Based on this framework, several studies have provided support for the importance of quality of life in adults and children, and its positive impact on family living and interpersonal relationships [2, 13]. The quality of life theory hypothesized that low level life satisfaction predicted adult psychiatric disorders such as depression, maladaptive coping strategies, and adverse clinical outcomes [15]. Later studies found similar associations with children's psychosocial functioning $[13,29]$. Based on the quality of life literature, Frisch [10] developed the quality of life therapy (QoLT) intervention to increase life satisfaction, and proposed 16 quality of life areas that should be addressed in the processes of QoLT (also, referred to as CASIO model). Van Napon et al. [30] evaluated a QoLT-based programme, which had positive impact on the parent-child relationship. Families initially identified their strengths, before developing and enhancing qualities such as self-esteem, communication, values and optimism. The intervention was provided for parents of children between pre-school and high school age. There has since been limited further research on the application of QoLT with families of children with different psychiatric disorders.

Taking into consideration previous evidence on treatment effectiveness for OCD, QoLT for mothers could enhance the benefits of CBT, at least in some families of children with OCD. Since QoLT is a new approach, in our knowledge to date there have been no studies that have evaluated its application in childhood OCD. This approach could be particularly important in countries where child psychiatric disorders carry a high degree of stigma, and a positive involvement of parents may be engaging with existing services. This was the rationale for this study, the aim of which was to evaluate the impact of QoLT with mothers of children with OCD symptoms referred to clinical services in Iran.

\section{Methods}

The research hypotheses were:

1. QoLT with mothers is associated with improvement in children's OCD and anxiety symptoms.

2. QoLT with mothers is associated with improved life quality and satisfaction among themselves and their children.

Setting, subjects and procedure

All 133 children (61 boys and 72 girls) consecutively referred over 3 months (March to May 2008) for treatment of anxiety-related problems by schools and clinics in the Esfahan region in Iran (with a population of 1,598,000) [27] to the joint Esfahan Education Organization Counseling Centre and the Psychiatric \& Counseling Centre were independently interviewed by researchers. Inclusion criteria were: age 6-18 years; diagnosis of OCD according to DSM-IV-TR for children [1]; and mothers consenting to participate in the treatment programme and the study. Exclusion criteria were the diagnoses of psychosis, pervasive developmental disorder and learning disability. Interviewers were six psychologists whose qualifications, were: MA degree (2), $\mathrm{PhD}$ (2), or studying towards a PhD degree (2). The interviewers initially identified 62 children who fulfilled inclusion criteria for the study. Three different psychologists trained in the use of DSM-IV criteria for OCD re-checked the 62 interview data, following which an OCD diagnosis was confirmed for 53 children and young people.

Mothers were invited to the Esfahan Psychiatric and Counseling Centre, and were provided with information for the therapy and the study. Forty-nine mothers gave informed consent and agreed to participate. They were then randomly allocated to two groups, by each mother being given a random number from 1 to 49 , based on which table, mothers with odd numbers remained on the waiting list and those with even numbers participated in therapy. In the experimental group, two mothers did not attend the first 
therapy session and two mothers did not complete all therapy sessions. In the control group, five children and their mothers did not complete the post-intervention measures. All control mothers were offered the intervention after the completion of the study. No other treatment, including medication, was offered during the 8 -week period of the study. Research ethics approval was granted locally in each of the two centres, and written informed consent was obtained from all mothers.

\section{The QoLT programme}

The programme was based on the QoLT framework [10]. Overall, this model uses some cognitive therapy techniques to activate constructive schemas in the context of increasing life satisfaction. These can be particularly helpful for unengaged, neglectful, emotive or over-protective parents, who have limited coping skills and low experiences of positive life events. The QoLT thus helps parents develop life management skills and gain life control, through the identification and pursuing of their needs, goals and wishes. The intervention aims at changing core QoLT concepts, attitudes, skills, strengths and positive schemas, and these in turn can promote lasting life satisfaction and sense of contentment.

The intervention offered strategies for 16 areas of life, and included a general model of problem solving on the five components of the CASIO model (Fig. 1). The five components include change in circumstances, attitudes, standards, importance (values), and other aspects of life applied to any of the 16 areas of life. QoLT also offered area-specific techniques [10]. A list of 20 techniques for all the areas of life was presented to participants in each session. With the support and assistance of the therapist, participants chose one or two related techniques, which they used as homework. These included: balanced lifestyle; lowering expectations; finding a meaning and purpose in life; increasing quality time with the child; fitness habits; increasing affection for the child; FAT (family, alone, together) time; accepting what one can not change; 'happiness' habits (sharing activities that have been found to increase happiness such as close relationships with friends and family); 'happiness diet' (concentrating on what makes people happy); 'colour purple' principle (focusing on what is considered good and beautiful in the world); 'happiness spillover' principle (this technique is based on the concept that happiness or unhappiness in one area of life can generate similar emotions in other areas of life); using humour; expanding one's interests; mental health day or hour (clients learn how, when in distress, to take a day off work or other responsibilities); positive addiction (encouraging mothers to find gratification, fun, flow and the love that they need in each life area); creativity routines; 'second option' (learning how to consult with a counselor on relationships difficulties); over thinking principle (learning how to stop their child's ruminations); and playing like a child (how adults play and enjoy). For a more detailed description of these techniques, see Frisch [10].

Most QoLT techniques were not directed specifically at issues related to OCD, but rather at all aspects of children's and families' lives. When participating mothers asked questions on their children's OCD symptoms, an explanation was provided by the therapist, with practical strategies based on the CBT model on how to best deal with the symptoms. In other words, CBT strategies were not structured within the QoLT programme and were not directed by the therapist, but were rather used as complementary to QoLT, and in response to mothers' questions.
Fig. 1 Five paths or CASIO model of life satisfaction, or QoLT
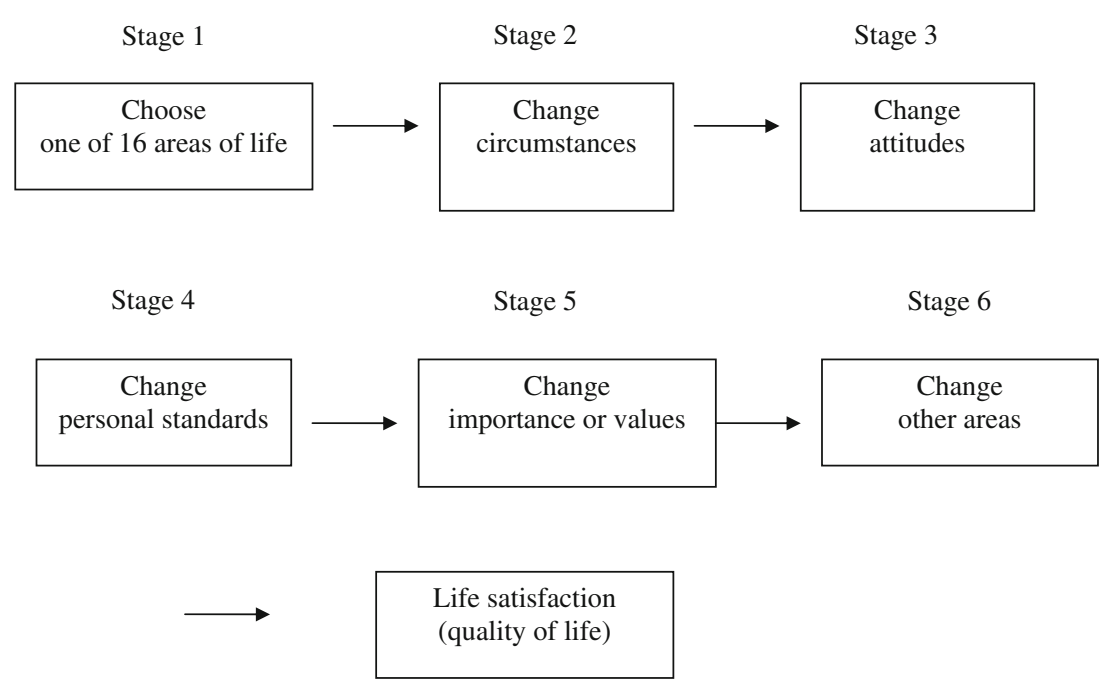
Treatment was provided by the first author, who had substantial experience in cognitive-behavioural therapy for OCD and 5 years experience of QoLT.

Treatment included eight 90-min sessions, over 4 weeks. Mothers attended two groups, each consisting of ten participants. Session 1 was devoted to describing the experiences of having a child with OCD, and encouraging participants to view OCD as a neuropsychiatric condition that was affected by quality of life. For example, "although OCD is a condition caused by brain-related factors, it is necessary at first to increase happiness in your life and your child's life; if you do not see reduction in OCD symptoms, introduce exposure and response prevention to your child in a positive manner and within a positive relationship". Quality of life was defined as the extent that one's most important needs, wishes and goals have been satisfied along 16 areas of life. The 16 areas of Frisch life satisfaction were then introduced and discussed, although usually not specifically in relation to OCD. After brainstorming about possible solutions for these problems, it was explained that for any life areas in which the family experienced low satisfaction, there are five strategies to increase satisfaction, under the acronym CASIO [10]:

1. C Circumstances change: circumstances could change in different ways, for example, if you are employed and unhappy with your job, you may seek career counselling in order to bring some changes in your working life.

2. A Attitudes change: sometimes, one's perceived characteristics or views may be distorted. In order to change attitudes, everyone has to answer questions like "what is really happening in my life?", and "what is my interpretation?"

3. S Standards change: it is important to set realistic goals and lowering standards. In this context, asking the following questions can be helpful: "are my goals and standards in this area of life realistic? Or, "what are realistic goals in this area?"

4. I Importance change: this strategy needs re-evaluating importance and priorities, and focusing on areas that are most important and changeable.

5. $O$ Other areas change: sometimes, people place emphasis on an area that is very difficult and slow to change, while focusing on other areas instead can boost their life satisfaction.

After explanation of the model and discussion, parents were asked to think of possible ways of improving their quality of life, as homework towards the next session.

Session 2 focused on children and interactive play with their child. Following discussion based on the CASIO model, the therapist linked the establishment of a positive and nurturing environment, which included positive and empathic interaction, with improvement in children's OCD symptoms. The latter were also targeted with CBT techniques. The importance of play with children and recreation time within the family were related to increasing family quality of life. Finally, the therapist introduced some skills for play, recreation and interaction with children, including: how to prepare play, a recreation list, time management for play and recreation, obstacles to play satisfaction, and coping with negative beliefs. Mothers were asked to increase play and recreation time, and to generate the use of these skills in their everyday life, as homework until the next session.

In sessions 3-8, participants focused on other areas of life, and used the CASIO model to implement changes in their life. In each session, following discussion on the previous homework and tasks, the therapist introduced skills to enhance change in each area, based on Frisch [10]. Positive interaction with children and play were considered in each session, and mothers' questions about managing OCD symptoms were answered based on both the CBT and quality of life models. The topics discussed in sessions 1-8 are presented in Table 1.

\section{Measures}

Children's Yale-Brown obsessive compulsive scale (CY-BOCS)

The CY-BOCS [24] is a 10-item structured, clinician-rated inventory of obsession and compulsion severity over the previous week. Five items assess core features of obsessions (time spent, interference, distress, resistance and control), and five items assess core features of compulsions (time spent, interference, distress, resistance and control). Each of the ten items is rated on a 5-point Likert scale ranging from 0 (absent) to 4 (extreme). Total possible scores range between 0 and 40. Psychometric evidence for the CY-BOCS is promising, with high internal consistency $(0.87-0.90)$ and strong convergent and divergent validity $(65,74)$. In Iran (Esfahan city), Mozafari and Abedi [18] evaluated the reliability of the Farsi version of the CYBOCS, and found high internal consistency for the total score (0.85), as well as for the obsessive and compulsive severity scores (0.78 and 0.79$)$.

\section{Quality of life inventory (QoLI)}

The QoLI [10] is a 32-item self-report scale. The items cover areas of life that have been empirically relevant to overall life satisfaction, and include: health, goals and values, work, play, home, finances, learning, self-esteem, creativity, helping, affection, friends, children, relatives, 
Table 1 Content of quality of life therapy sessions

\section{Session 1}

Introduce participants

Mother's experiences of having a child with OCD

Review goals

Review QoLT and rationale

Discuss 16 areas of life satisfaction

Determine difficult areas

Homework: think about how do we improve our quality of life

Session 2

Review QoLT progress

Review homework

Define and provide examples of CASIO model

Discuss positive interaction with children and play, and present skills in these areas

Homework: use skills in everyday life; increase play and family recreation time

Session 3

Review CASIO model

Review homework

Discuss health and self-esteem topics, and present related skills

Homework: use skills in everyday life; increase play and family recreation time

Session 4

Review model and homework

Discuss goals, values and learning areas, and present related skills

Homework: use skills in everyday life; increase play and family recreation time

Session 5

Review model and homework

Discuss community, neighbourhood and creativity, and present related skills

Homework: use skills in everyday life; increase play and family recreation time

Session 6

Review model and homework

Discuss work and home areas, and present related skills

Homework: use skills in everyday life; increase play and family recreation time

Session 7

Review model and homework

Discuss affection, employment and finances, and present related skills

Homework: use skills in everyday life; increase play and family recreation time

Session 8

Review model and homework

Review all treatment sessions

Transition to being own QoLT therapist

Further study and work in QoLT

neighbourhood, and community. Each item is rated on a 3point scale in terms of its importance to the respondent's overall happiness and satisfaction $(0=$ not important to
$2=$ extremely important), and the extent to which the respondent is satisfied $(-3=$ very dissatisfied to $3=$ very satisfied). Overall life satisfaction is computed by summed product of importance for each area, and ranging from -6 to 6 . In the supplementary part of the questionnaire, respondents indicate any problems that interfere with their satisfaction in each area. The predictive and treatment validity of the QoLI have been established [11]. Test-retest coefficients for the QoLI range from 0.80 to 0.90 , and internal consistency coefficients range from 0.77 to 0.89 , based on a study of three clinical and non-clinical samples [7]. The validity of the QoLI has also been reported [8,9] in comparison with several quality of life measures such as the QoLI, with a correlation of $0.75(p<0.001)$ [5]. The QoLI was completed by mothers.

Brief multidimensional student's life satisfaction scale (BMSLSS)

The BMSLSS [26] is a 6-item scale used to assess the domains of life satisfaction in children and adolescents. Items assess satisfaction on six domains: family life, friendships, school experience, self-living environment, and global life satisfaction. The response options are scored on 7-point Likert scale ranging from 'terrible' to 'delighted'. Acceptable internal consistency has been established; with alphas between 0.75 and 0.81 , as well as satisfactory construct validity [26].

\section{Revised children's manifest anxiety scale (RCMAS)}

The RCMAS [22] is a 37-item self-report questionnaire for children. It measures the presence or absence of anxietyrelated symptoms ('yes' or 'no' answers). The measure is most widely used for assessing childhood anxiety, and has been demonstrated to be reliable across different gender, racial, and age groups [22].

Statistical analysis

Descriptive statistics with computations of means and standard deviations were used for all measures: CYBOCS, obsessions; CY-BOCS, compulsions; CY-BOCS, total; QoLI; RCMAS, and five domains of BMSLSS. The normality assumption was checked by looking at histograms of the standardized residuals. We also checked that there was no obvious association between the residuals and the predicted values. The Pearson correlation test was used to establish associations between the measures. Analysis of covariance was used for each variable, to examine changes after treatment across the two groups, adjusting for baseline scores. The Levinson test was used to confirm that the variability was equal in the two groups. 


\section{Results}

Overall, mothers of 40 children with OCD ( 18 boys and 22 girls) participated in the study, 20 in the experimental group (mean age 11.35 years) and 20 in the control group (mean age 12.15 years). The boys' mean age was 10.8 years and the girls' mean age was 12.5 years. Table 2 presents the mean and standard deviation pre- and posttreatment scores for the two groups. There were no significant differences between two groups on any variables at the baseline assessment. Since there was no significant relationship between children's age or gender and any of the outcome measures, these variables were not included in further analysis. Mothers' and children's measures were not significantly correlated at the first assessment.

Table 3 presents the analysis of covariance findings. As Table 3 shows, there were significant differences between the two groups on the CY-BOCS, obsessions $(F=95.64$, $p<0.001)$, compulsions $(F=47.34, p<0.001)$ and total scores $(F=132.76, p<0.001)$.

We also compared scores on the ten CY-BOCS items between the experimental and the control group. As Table 4 shows, in the post-intervention ratings, children in the experimental group reported less time occupied by obsessive thoughts $(F=4.03, p=0.045)$ and compulsive behaviours $(F=18.48, p<0.001)$; less interference due to obsessive thoughts $(F=24.61, p<0.001)$ and compulsive behaviours $(F=17.9, p<0.001)$; less distress associated with obsessive thoughts $(F=46.16, p<0.001)$ and compulsive behaviours $(F=29.11, p<0.001)$; less resistance to obsessive thoughts $(F=24.42, p<0.001)$ and compulsive behaviours $(F=9.31, p<0.004)$; and more control over obsessive thoughts $(F=42.37, p<0.001)$ and compulsive behaviours $(F=24.25, p<0.001)$.

There was also significant difference in the reduction of children's RCMAS scores $(F=33.99, p<0.001)$ and increase of mothers' QoLI scores between the two groups $(F=46.10, p<0.001$ ) (also Table 3 ). Table 5 presents the changes in children's life satisfaction outcome scores for the two groups. Statistically significant differences were found on the global aspect $(F=32.39, p<0.001)$, family $(F=12.30, \quad p<0.001), \quad$ self-living $\quad(F=21.94$, $p<0.001)$, and environment life satisfaction $(F=34.43$, $p<0.001)$. No significant differences were established between the two groups on satisfaction with friendships and school.

\section{Discussion}

This study described the application and preliminary evaluation of the QoLT for mothers of children with OCD in a mental health service in Iran. The exploratory findings are promising, as they indicate positive impact on maternal and child-rated outcome measures following the intervention. To date there has been no evaluation of the effect of QoLT on OCD, although a previous QoLT targeted adults with depression, who improved post-intervention [12]. The findings are consistent with previous studies on the benefits of involving parents and families in the treatment of children with OCD, often extending CBT techniques to the whole family, or deploying them in parallel with parents and children [30]. It is important to acknowledge that, like other intervention programmes arising from different theoretical and therapeutic frameworks, QoLT is not a 'pure'

Table 3 Analysis of covariance on intervention effects

\begin{tabular}{llllll}
\hline Measure & Source & $d f$ & Mean square & \multicolumn{1}{l}{ S } & Sig \\
\hline CY-BOCS, obsessions & Pre-test & 1 & 149.93 & 67.96 & 0.000 \\
& Group & 1 & 210.98 & 95.64 & 0.000 \\
CY-BOCS, compulsions & Pre-test & 1 & 100.63 & 32.64 & 0.000 \\
& Group & 1 & 146.22 & 47.43 & 0.000 \\
CY-BOCS, total & Pre-test & 1 & 245.12 & 45.70 & 0.000 \\
& Group & 1 & 712.03 & 132.76 & 0.000 \\
QoLI & Pre-test & 1 & 43.07 & 41.63 & 0.000 \\
& Group & 1 & 47.69 & 46.10 & 0.000 \\
RCMAS & Pre-test & 1 & 103.47 & 33.99 & 0.000 \\
& Group & 1 & 213.47 & & \\
\hline
\end{tabular}

Table 2 Mean and standard deviation scores for pre- and post-treatment outcome measures

\begin{tabular}{|c|c|c|c|c|c|c|c|c|c|}
\hline \multirow[t]{3}{*}{ Measure } & \multirow[t]{3}{*}{ Range } & \multicolumn{4}{|c|}{ Intervention group } & \multicolumn{4}{|c|}{ Control group } \\
\hline & & \multicolumn{2}{|l|}{ Pre } & \multicolumn{2}{|l|}{ Post } & \multicolumn{2}{|l|}{ Pre } & \multicolumn{2}{|l|}{ Post } \\
\hline & & M & SD & M & SD & M & SD & M & SD \\
\hline CY-BOCS, obsessions & 0 to 20 & 10.90 & 2.17 & 6.10 & 2.29 & 10.35 & 2.39 & 10.25 & 2.63 \\
\hline CY-BOCS, compulsions & 0 to 20 & 9.05 & 1.79 & 5.05 & 1.43 & 9.50 & 2.32 & 9.25 & 3.04 \\
\hline CY-BOCS, total & 0 to 40 & 19.95 & 2.60 & 11.15 & 2.83 & 19.85 & 3.04 & 19.50 & 3.91 \\
\hline QoLI & -6 to 6 & 0.55 & 1.66 & 2.85 & 1.18 & 0.45 & 1.60 & 0.60 & 1.69 \\
\hline RCMAS & 0 to 28 & 19.80 & 2.74 & 14.40 & 2.37 & 18.75 & 3.02 & 18.5 & 3.47 \\
\hline
\end{tabular}


Table 4 Y-BOCS items scores in the intervention and control group

\begin{tabular}{|c|c|c|c|c|c|c|c|c|c|c|}
\hline \multirow[t]{3}{*}{ Group } & \multicolumn{4}{|c|}{ Intervention group } & \multicolumn{4}{|c|}{ Control group } & \multirow[t]{3}{*}{$F$} & \multirow[t]{3}{*}{$P$} \\
\hline & \multicolumn{2}{|l|}{ Pre } & \multicolumn{2}{|l|}{ Post } & \multicolumn{2}{|l|}{ Pre } & \multicolumn{2}{|l|}{ Post } & & \\
\hline & M & SD & M & SD & M & SD & M & SD & & \\
\hline \multicolumn{11}{|l|}{ Item } \\
\hline 1. Time occupied by obsessive thoughts & 2.25 & 0.78 & 1.60 & 0.75 & 2.30 & 0.80 & 2.00 & 0.85 & 4.30 & 0.040 \\
\hline 2. Interference due to obsessive thoughts & 2.85 & 0.58 & 1.80 & 0.83 & 2.55 & 0.68 & 2.50 & 0.88 & 24.61 & 0.000 \\
\hline 3. Distress associated with obsessive thoughts & 2.05 & 0.68 & 1.15 & 0.74 & 2.05 & 0.75 & 2.30 & 0.80 & 46.16 & 0.000 \\
\hline 4. Resistance against obsessions & 1.45 & 0.51 & 0.75 & 0.63 & 1.45 & 0.60 & 1.70 & 0.57 & 24.42 & 0.000 \\
\hline 5. Degree of control over obsessive thoughts & 2.25 & 0.63 & 0.85 & 0.67 & 2 & 0.79 & 1.75 & 0.63 & 42.37 & 0.000 \\
\hline 6. Time spent performing compulsive behaviours & 1.60 & 0.59 & 0.85 & 0.48 & 1.70 & 0.65 & 1.65 & 0.74 & 18.48 & 0.000 \\
\hline 7. Interference due to compulsive behaviours & 1.50 & 0.51 & 0.85 & 0.48 & 1.40 & 0.50 & 1.45 & 0.60 & 17.09 & 0.000 \\
\hline 8. Distress associated with compulsive behaviours & 2.25 & 0.71 & 1.05 & 0.60 & 2.20 & 0.76 & 2.10 & 0.96 & 29.11 & 0.000 \\
\hline 9. Resistance against compulsions & 1.85 & 0.67 & 1.30 & 0.57 & 2.05 & 0.88 & 1.95 & 0.88 & 9.31 & 0.004 \\
\hline 10. Degree of control over compulsive behaviours & 1.80 & 0.69 & 1.00 & 0.64 & 2.15 & 0.81 & 2.10 & 0.78 & 24.25 & 0.000 \\
\hline
\end{tabular}

Table 5 Children's life satisfaction (BMSLSS domains) in the intervention and control group

\begin{tabular}{|c|c|c|c|c|c|c|c|c|c|c|}
\hline \multirow[t]{3}{*}{ Group } & \multicolumn{4}{|c|}{ Intervention group } & \multicolumn{4}{|c|}{ Control group } & \multirow[t]{3}{*}{$F$} & \multirow[t]{3}{*}{$P$} \\
\hline & \multicolumn{2}{|l|}{ Pre } & \multicolumn{2}{|l|}{ Post } & \multicolumn{2}{|l|}{ Pre } & \multicolumn{2}{|l|}{ Post } & & \\
\hline & M & SD & M & SD & M & SD & M & SD & & \\
\hline \multicolumn{11}{|l|}{ Domain } \\
\hline Global & 3.55 & 1.05 & 5.00 & 0.72 & 3.80 & 0.89 & 3.85 & 0.74 & 32.39 & 0.000 \\
\hline Family & 3.50 & 1.05 & 4.90 & 0.64 & 3.70 & 0.73 & 4.10 & 0.78 & 32.39 & 0.001 \\
\hline School & 2.80 & 0.76 & 3.10 & 0.71 & 3.05 & 0.88 & 3.20 & 0.69 & 12.30 & 0.73 \\
\hline Friends & 4.70 & 0.80 & 4.35 & 0.87 & 4.55 & 0.88 & 4.45 & 0.82 & 0.15 & 0.70 \\
\hline Self & 3.20 & 0.89 & 4.85 & 0.67 & 3.70 & 0.97 & 3.95 & 0.75 & 21.98 & 0.000 \\
\hline Living environment & 2.70 & 0.73 & 4.95 & 0.94 & 3.00 & 0.91 & 3.60 & 0.59 & 17.64 & 0.000 \\
\hline
\end{tabular}

modality. Although not primarily adopting CBT techniques, there was overlap in a number of skills and tasks discussed with mothers in relation to a more positive approach to general life functioning, as well as in relation to their children's symptoms and behaviours. Therefore, the findings could have implications for the identification of families who would benefit from an intervention such as QoLT complementing individual CBT.

Both children and mothers rated their quality of life as significantly improved following the intervention, in domains well beyond the OCD symptomatology. In particular, children reported improved life satisfaction in their family and immediate living environment, which can be explained by the family focus of the intervention. In contrast, there was no significant change in their satisfaction with school and friendships, which indicates the need for additional support in the school setting. The future use of CBT and QoLT techniques by teachers would be an interesting expansion of the existing programme.
Mothers' perceptions of improved quality of life also reflect the primary objectives of the intervention. These could be related to several reasons, although the underlying mechanisms and process were beyond the remit of this study. Rachman [21] proposed a therapeutic model of improvement in mothers' mood and coping strategies through changes in some life factors, which could then impact on their family environment and their children's emotional state, and this was supported by subsequent findings [23], although the specific mechanisms through which this theory can be applied to OCD remain unclear. A hypothesis for future research is whether increasing life satisfaction is particularly important for depressed mothers, while focusing on time management (learning how to divide time and consider all their children's needs) might be more therapeutic for predominantly anxious mothers.

Second, by encouraging mothers to lower expectations, alter priorities, and participate in creative activities may have helped reduce perfectionism and rigidity, hence 
impact on children's OCD psychopathology. Third, reframing mothers' understanding of and attitudes towards OCD into a more positive view towards OCD symptoms, according to the CASIO model of attitudinal change may have had positive effect on the children. Newth and Rachman [19] described OCD as a particularly 'secretive' disorder, with parents and children fearing that the nature of the symptoms might lead others to render them as 'crazy'. QoLT, like other positive psychology interventions, teaches practical skills to satisfy important needs and is focused on strengths, may thus activate motivation for change.

According to the last national census [27], the population of Iran is quite young, with an average age of less than 20 years. Children are referred by counsellors and teachers to psychiatry and psychology services, but in small towns only pharmacological treatment is available. Many physicians are reluctant to use drugs as first line of treatment for common adolescent mental health problems, and these challenges are compound by families' fears of stigma. Consequently, the development of engaging and resourceeffective targeted intervention programmes is crucial, especially if these can hopefully be implemented in the future by non-specialists working with children and their families. Such implications could be generalizable to other societies with a similar status of needs and service requirements.

The results of this study should be interpreted with caution, because of several limitations. The research design did not include an active comparison group such as CBT. Thus, future studies are needed to compare the specific effect of QoLT or combined QoLT and CBT, with CBT only or behavioural therapy (such as relaxation therapy), to investigate the specificity of effect. Involvement of children and fathers in the programme; and inclusion of measures of the duration of OCD, socioeconomic factors, parental psychopathology, family relationships, and the process of therapy (rated by clients and therapist) would help build a better understanding of the mechanisms of change. Other limitations were the lack of treatment manualization and its application by one experienced therapist. The sample may not have been representative of this client group, as children were referred to a specialist rather than generic mental health service. No intention to treat analysis was conducted with the initial sample of 49 mothers. As the findings are based on post-intervention assessments; it was not possible to establish the sustainability of improvement through medium- and long-term follow-ups. In future, it will be important to take into consideration child- and family-related characteristics (such as help-seeking, parenting skills and family functioning) to establish which families might benefit from a combined QoLT and CBT intervention, and which by single treatment modalities. Within these limitations, the findings have some potentially important implications. Approaches such as group QoLT can be particularly applicable and cost-effective in countries like Iran, especially in small towns and rural areas, where specialist resources are sparse, including the availability of trained CBT practitioners; waiting lists are lengthy; and families must commute long distances to access specialist centres.

Acknowledgments This research was accomplished during the period of the first author's sabbatical leave that was supported by the University of Esfahan in Iran, in collaboration with the Greenwood Institute of Child Heath, of the University of Leicester in the UK. We wish to thank both Universities; Dr John Bankart for his helpful suggestions on the statistical analysis; and the Esfahan Counseling and Psychiatric Clinics, especially the Esfahan psychiatric and Counseling Centre, for their generous co-operation. Above all, we are grateful to all the mothers and children who participated in the study.

\section{References}

1. American Psychiatric Association (2000) Diagnostic and statistical manual of mental disorders (4th edn TR). American Psychiatric Association, Washington DC

2. Antaramian SP, Hhebner ES, Valois RF (2008) Adolescent life satisfaction. Appl Psychol Int Rev 57:112-126

3. Derisley J, Libby S, Clark S, Reynolds S (2005) Mental health, coping and family-functioning in parents of young people with obsessive-compulsive disorder and with anxiety disorders. Br J Clin Psychol 44:439-444

4. Ehiobuch I (1989) Obsessive-compulsive neurosis in relation to parental child-rearing patterns among Greek, Italian and AngloAustralian subjects. Acta Psychiatr Scand 78(Suppl 344):115120

5. Ferrers CE, Powers MJ (1992) Psychometric assessment of quality of life index. Res Nurs Health 15:29-38

6. Freeman JB, Choate-Summers ML, Moore PS, Garcia AM, Sapyta JJ, Leonard $\mathrm{Hl}$ et al (2007) Cognitive behavioral treatment for young children with obsessive-compulsive disorder. Biol Psychiatry 61:337-343

7. Frisch MB (1992) Use of the quality of life inventory in problem assessment and treatment planning for cognitive therapy of depression. In: Freeman F, Dattilio F (eds) Comprehensive casebook of cognitive therapy. Plenum Press, New York, pp 2752

8. Frisch MB (1993) The quality of life inventory: a cognitivebehavioral tool for complete problem assessment, treatment planning, and outcome evaluation. Behavior Ther 16:42-44

9. Frisch MB (2004) Use of the QoLI or quality of life inventory in quality of life therapy and assessment. In: Maruish MR (ed) The use of psychological testing for treatment planning and outcome assessment, vol 3, instruments for adults. Erlbaum, Manwah, NJ, pp 749-798

10. Frisch MB (2006) Quality of life therapy: applying a life satisfaction approach to positive psychology and cognitive therapy. Wiley and Sons, Hoboken, NJ

11. Frisch MB, Clark MP, Rouse SV, Rudd MD, Paweleck J, Greenstone A (2005) Predictive and treatment validity of life satisfaction and quality of life inventory. Assessment 12:66-87

12. Grant G, Salcedo V, Hynan LS, Frisch MB (1995) Effectiveness of quality of life therapy. Psychol Rep 76:1203-1208 
13. Huebner ES, Suldo S, Smith L, McKnight C (2004) Life satisfaction in children and youth: empirical foundations and implication for school psychologists. Psychol Sch 41:81-94

14. Knox LS, Albano AM, Barlow DH (1996) Parental involvement in the treatment of childhood compulsive disorder: a multiple baseline examination incorporating parents. Behavior Ther 27:93-114

15. Koivumaa-Honkanen H, Honkanen R, Antikainen R, Hintikka J, Viinamaki H (1996) Self-reported life satisfaction and treatment factors in patients with schizophrenia, major depression and anxiety disorder. Acta Psychiatr Scand 99:377-384

16. March JS, Mulle K (1998) OCD in children and adolescents: cognitive-behavioral treatment manual. Guilford Press, New York

17. Merkel WT, Pollard CA, Wiener RL, Staebler CR (1993) Perceived parental characteristics of patients with obsessive-compulsive disorder, depression, and panic disorder. Child Psychiatry Hum Dev 24:49-57

18. Mozafari M, Abedi MA (2003) Reliability and validity of the Children's Yale-Brown obsessive-compulsive scale in an Iranian sample. Unpublished report, Esfahan Education Organization

19. Newth S, Rachman S (2001) The concealment of obsessions. Behavior Research Ther 39:457-464

20. Piacentini J (1999) Cognitive behavior therapy for child and adolescent OCD. Child Adolesc Clin North Am 8:599-618

21. Rachman S (1981) Part 1. Unwanted intrusive cognitions. Adv Behav Res Ther 3:89-99

22. Reynolds CR, Richmond OB (1997) What I think and feel: a revised measure of children's manifest anxiety. J Abnorm Child Psychol 25:15-20
23. Ricciardi J (1995) Depressed mood is related to obsessions, but not to compulsions in obsessive-compulsive disorder. J Anxiety Disord 9:249-256

24. Scahill L, Riddle MA, McSwiggin-Hardin M, Ort SI, King RA, Goodman WK et al (1997) Children's Yale-Brown obsessivecompulsive scale: reliability and validity. J Am Acad Child Adolesc Psychiatry 36:844-852

25. Seligman MEP, Csikszentminalyi M (2000) Positive psychology: an introduction. Am Psychol 55:5-14

26. Seligson JL, Huebner ES, Valois RF (2005) An investigation of a brief satisfaction scale with elementary school children. Soc Indic Res 73:355-374

27. Statistical Centre of Iran (2006) Statistical pocketbook of the Islamic Republic of Iran. Statistical Center of Iran, Tehran

28. Steketee G, Van Noppen B (2003) Family approaches to treatment for obsessive compulsive disorder. J Family Psychother 14:55-71

29. Suldo S, Huebner ES (2005) Very satisfied youth: advances in quality of life research. Springer, New York

30. Van Nappon B, Steketee G, Mccorkle BH, Pato M (1997) Group and multifamily behavioral treatment for obsessive compulsive disorder: a pilot study. J Anxiety Disord 11:431-446

31. Waters T, Barrett PM, March JS (2001) Cognitive-behavioral family treatment of childhood obsessive-compulsive disorder: preliminary findings. Am J Psychother 3:173-184

32. Watson HJ, Rees CS (2008) Meta-analysis of randomized, controlled treatment trials for pediatric obsessive compulsive disorder. J Psychol Psychiatry 49:489-498 